\title{
Lutz Haertlein
}

\section{Exekutionsintervention und Haftung}

\author{
Haftung wegen unbegründeter Geltendmachung von Drittrechten in der \\ Zwangsvollstreckung
}

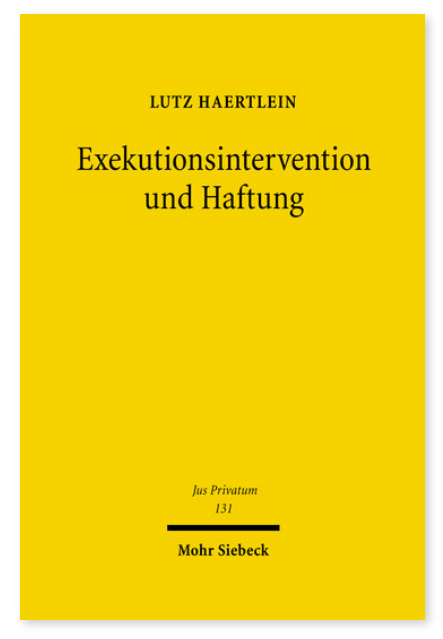

2008. XXXIX, 612 Seiten. JusPriv 131

ISBN 978-3-16-151208-7

DOI 10.1628/978-3-16-151208-7

eBook PDF 149,00€

ISBN 978-3-16-149404-8

Leinen $149,00 €$
In der zivilprozessualen Einzelzwangsvollstreckung gilt das Zweiparteienprinzip. Dennoch werden nicht selten Dritte in ihren Rechten betroffen, weil das Vollstreckungsrecht dem Vollstreckungszugriff auf schuldnerfremde Gegenstände kaum

vorbeugt. Betroffene Dritte sind vielmehr gehalten, aktiv gegen die Zwangsvollstreckung vorzugehen (Exekutionsintervention). Andererseits ermöglicht es die Intervention, denkbar weitgehend auf die Vollstreckung einzuwirken (bis hin zur Aufhebung), wobei zunächst die bloße Behauptung eines Drittrechts am Vollstreckungsgegenstand ausreichen kann. Dementsprechend unsicher ist es typischerweise, ob die Maßnahme begründet ist. Lutz Haertlein geht der Frage nach der Haftung des Intervenienten gegenüber dem Vollstreckungsgläubiger bei unbegründeter Intervention nach. Zur Klärung dieses Sachverhalts betrachtet er zunächst die rechtlichen Regelungen der verschiedenen Interventionsmöglichkeiten. Im Zentrum seiner Untersuchung stehen die Bestimmung des Haftungszwecks der Sicherheitsleistung eines Intervenienten, die Risikohaftung aus prozessualer Veranlassung und die Haftungsprivilegierung bei der Inanspruchnahme staatlicher Rechtspflegeverfahren. Desweiteren beschäftigt sich der Autor mit dem Bereicherungsausgleich im Verhältnis zwischen Vollstreckungsgläubiger und schuldner und dem Intervenienten, das sich nicht in die bereicherungsrechtliche Kategorisierung von

Mehrpersonenverhältnissen einfügen lässt, sowie mit der Frage, unter welchen Voraussetzungen zwischen Prozessparteien als solchen eine materiellrechtliche Sonderverbindung besteht.

Lutz Haertlein Geboren 1964; Studium der Rechtswissenschaften in Tübingen und München; 1998 Promotion; seit 1998 Rechtsanwalt; 2006 Habilitation; Privatdozent für Bürgerliches Recht, Handels- und Gesellschaftsrecht, Zivilverfahrensrecht in Bonn; Lehrstuhlvertretungen an den Universitäten Heidelberg und Leipzig.
Jetzt bestellen:

https://mohrsiebeck.com/buch/exekutionsintervention-und-haftung-9783161512087?no_cache=1

order@mohrsiebeck.com

Telefon: +49 (0)7071-923-17

Telefax: +49(0)7071-51104 